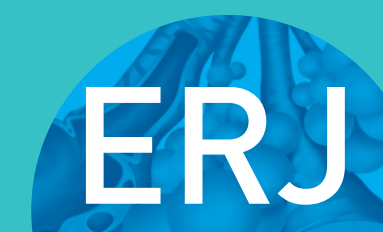

open research

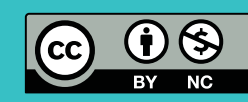

\section{Nickel allergy is associated with wheezing and asthma in a cohort of young German adults: results from the SOLAR study}

Laura Kolberg (1) ${ }^{1,2,3}$, Felix Forster ${ }^{1,3}$, Jessica Gerlich ${ }^{1,3}$, Gudrun Weinmayr ${ }^{4}$, Jon Genuneit $\mathbb{1}^{4,5}$, Doris Windstetter ${ }^{1}$, Christian Vogelberg ${ }^{6}$, Erika von Mutius $\mathbb{1}^{3,7}$, Dennis Nowak ${ }^{1,3}$, Hans Drexler ${ }^{8}$, Torsten Schäfer ${ }^{9}$ and Katja Radon ${ }^{1,3,10}$

\section{ABSTRACT}

Background: Nickel allergy is the most prevalent contact allergy. It belongs to a different hypersensitivity type to asthma and rhinoconjunctivitis. The aim of this analysis was to assess whether self-reported nickel allergy is associated with incident wheezing, asthma and rhinoconjunctivitis in young German adults, taking into account potential effect modification by sex.

Methods: In total, 2051 (70.6\%) participants aged 19-24 years took part in the second phase of SOLAR (Study on Occupational Allergy Risks), a follow-up study of ISAAC II (the second phase of the International Study of Asthma and Allergies in Childhood) in Germany. Self-reported nickel allergy, as well as having pierced ears, and the three outcomes incident wheezing, asthma and rhinoconjunctivitis, were analysed stratified for sex. Logistic regression adjusted for potential confounders was performed.

Results: An association between self-reported nickel allergy and incident wheezing was observed for men and women, while only in males did pierced ears show a significant association with the outcome (adjusted OR 2.26, 95\% CI 1.10-4.62). Also only in males, self-reported nickel allergy was associated with elevated odds for incident asthma (adjusted OR 4.34, 95\% CI 1.22-15.41). Neither in men nor in women was a significant association observed for incident rhinoconjunctivitis.

Conclusion: Our results suggest that self-reported nickel allergy is associated with incident wheezing. Whether this association is due to environmental or genetic predisposition, or due to an overlap of the mechanisms of type I and type IV hypersensitivity, needs to be elucidated.

@ERSpublications

Self-reported nickel allergy is associated with incident wheezing in young German males and females, and with incident asthma in males, whereas no significant association was observed for self-reported nickel allergy and incident rhinoconjunctivitis http://bit.ly/2YHmwBA

Cite this article as: Kolberg L, Forster F, Gerlich J, et al. Nickel allergy is associated with wheezing and asthma in a cohort of young German adults: results from the SOLAR study. ERJ Open Res 2020; 6: 00178-2019 [https://doi.org/10.1183/23120541.00178-2019].

This article has supplementary material available from openres.ersjournals.com.

Received: 19 July 2019 | Accepted after revision: 04 Dec 2019

Copyright @ERS 2020 This article is open access and distributed under the terms of the Creative Commons Attribution Non-Commercial Licence 4.0. 


\section{Introduction}

Nickel allergy, caused by skin contact to nickel, is the most common contact allergy in children, adolescents and adults. It is a cell-mediated hypersensitivity, where allergen-specific T-cells and memory T-cells proliferate. These memory $\mathrm{T}$-cells are activated after renewed contact to nickel, resulting in inflammation [1]. With a point prevalence of $9.8-27.5 \%$, it affects women more often than men (prevalence 2.1-5.1\%) in all age groups [2-5]. In females, contact with earrings plays a major role in the sensitisation process $[3,6]$. In 1994, the European Union adopted legislation to prevent further increase in nickel allergy. It has been in full force since 2001 and limits contact to nickel-releasing objects that are in direct or prolonged contact with the skin such as jewellery, watches and watch straps, buttons, and zips [7, 8]. So far, the restriction has been revised a few times and the nickel release of consumer objects further limited [9].

Like nickel allergy, asthma and rhinoconjunctivitis are high-prevalence diseases, especially in younger age groups $[10,11]$. They are IgE mediated hypersensitivities, where naive T-cells develop into T-helper cells that produce cytokines. IgE produced by B-cells binds to mast cells and basophils. Allergen exposure leads to cellular degranulation, and the release of cytokines and chemokines [12]. While since 1973, many cases of asthma [13-16] and rhinitis/rhinoconjunctivitis $[14,17,18]$ due to the inhalation of nickel have been reported, analyses of the association between nickel allergy, and atopy, atopic dermatitis [3, 6, 11, 19], hand dermatitis $[4,11,20]$, and asthma or rhinoconjunctivitis [4, 21-24] have revealed conflicting results. Some population-based analyses and a record linkage of two registers concluded that there is no association between nickel allergy and asthma or rhinitis [11, 16-18]. In contrast to these results, GüL et al. [24] analysed data from 40 asthmatics and found an association with nickel allergy. Although the risk of developing asthma differs between males and females, with a reversal of prevalence in puberty, most studies did not analyse data from males and females separately [25]. Also lacking is an analysis focusing solely on the association of nickel allergy with incident wheezing, asthma and rhinoconjunctivitis in a general-population setting.

We therefore aimed to assess whether self-reported nickel allergy is associated with incident wheezing, asthma and rhinoconjunctivitis in young German adults and whether the effect is modified by sex. For this, we separately investigated longitudinal data from males and females from a population-based cohort study.

\section{Methods \\ Study population}

The present study population consisted of participants in the population-based cohort study SOLAR (Study on Occupational Allergy Risks). Details of the study design have been described elsewhere [26]. In short, SOLAR, with two German study centres in Munich and Dresden, is the follow-up study of ISAAC II (the second phase of the International Study of Asthma and Allergies in Childhood) [27]. ISAAC II was conducted in 1995-1996 and data from 6399 children (response rate 85.3\%) aged 9-11 years were collected by means of parental questionnaires. These validated questionnaires included questions on atopic and respiratory symptoms, and on potential risk factors [27].

In 2002-2003, the then 16-18-year-old ISAAC II participants were re-contacted and 3785 of them (response rate $77.4 \%$ ) took part in SOLAR I. Of those, 2051 young adults (response rate 70.6\%) aged 19-24 years participated in the second follow-up (SOLAR II) during 2007-2009. The SOLAR questionnaires included, among others, questions on respiratory and atopic symptoms as well as questions on environmental and occupational risk factors. Mainly, they were adopted from the ECRHS (European Community Respiratory Health Survey) and ISAAC [28, 29].

Affiliations: ${ }^{1}$ Institute and Clinic for Occupational, Social and Environmental Medicine, University Hospital, LMU Munich, Munich, Germany. ${ }^{2}$ Institute for Medical Informatics, Biometry, and Epidemiology, LMU Munich, Munich, Germany. ${ }^{3}$ Comprehensive Pneumology Center Munich, Member of German Centre for Lung Research, Munich, Germany. ${ }^{4}$ Institute of Epidemiology and Medical Biometry, Ulm University, Ulm, Germany. ${ }^{5}$ Pediatric Epidemiology, Hospital for Children and Adolescents, University of Leipzig Medical Center, Leipzig, Germany. ${ }^{6}$ Paediatric Dept, University Hospital Carl Gustav Carus, TU Dresden, Dresden, Germany. ${ }^{7}$ Dr. v. Haunersches Kinderspital, University Hospital, LMU Munich, Munich Germany. ${ }^{8}$ Dept of Occupational, Social and Environmental Medicine, University of Erlangen-Nuremberg, Erlangen, Germany. ${ }^{9}$ Dermatologische Praxis Prof. Dr. med. Torsten Schäfer, Immenstadt, Germany. ${ }^{10}$ Munich Center of Health Sciences (MC-Health), Munich, Germany.

Correspondence: Katja Radon, LMU Munich, Ziemssenstr. 1, 80336 Munich, Germany. E-mail: katja.radon@ med.lmu.de 
In the present analysis, data from the 2051 participants who took part in all three study phases were analysed. SOLAR I is considered the baseline and SOLAR II, the follow-up. As a source of information for some potential confounders, data from ISAAC II were used.

Written informed consent was obtained from the participants or their legal guardians. The ethical committees of the Medical Faculty of the University of Dresden, the Bavarian Chamber of Physicians and the University of Ulm approved the study phases.

\section{Outcomes}

The primary outcome of these analyses was incident wheezing, defined as no wheezing at baseline and current wheezing at follow-up. Wheezing, thereby, was defined as either wheezing or whistling in the chest without cold or the use of asthma medication during the last 12 months prior to the survey.

Incident asthma and incident rhinoconjunctivitis were considered secondary outcomes. They were defined analogously to incident wheezing as no symptoms of asthma or rhinoconjunctivitis at baseline and current symptoms at follow-up. The definition of asthma consisted of having physician-diagnosed asthma and either wheezing or whistling in the chest without cold or use of asthma medication during the last 12 months prior to the survey. Sneezing and having a runny or blocked nose without a cold accompanied by itchy or watery eyes within the previous 12 months before the survey characterised symptoms of rhinoconjunctivitis.

Only participants without asthma, wheezing or rhinoconjunctivitis at baseline (SOLAR I) were included in the analyses comparing participants without outcome at SOLAR I with those with outcome at SOLAR II.

\section{Exposures}

As exposure variables, we considered self-reported nickel allergy or having pierced ears as an indirect measurement for nickel allergy. In the questionnaires of SOLAR I and SOLAR II, the participants were asked whether they were allergic to nickel (question in SOLAR I and SOLAR II: "Are you allergic to nickel (e.g. earrings, jeans buttons, watchstraps)?"). Based on this information, two categories were created: those who reported nickel allergy at any time ("ever nickel allergy" group) and those who reported nickel allergy neither at SOLAR I nor at SOLAR II ("never nickel allergy" group). In SOLAR II, the participants were additionally asked if they had pierced ears (yes or no), which was considered as a second exposure variable.

\section{Potential confounders}

Based on the literature $[19,30]$, the following variables were taken into account as potential confounders: smoking status (never or ever), parental and participant's socioeconomic status (SES) (high or low), study centre (Dresden or Munich), and parental history of asthma (for the analyses of wheezing and asthma) and rhinitis (for the analyses of rhinoconjunctivitis) (yes or no). Age was not considered a confounder because all participants were about the same age.

Participants who had ever smoked were considered smokers and the others as never-smokers. School attendance for $\geqslant 12$ years was assumed to correspond to a high SES and $<12$ years of school implied low SES. Parental history of asthma or rhinitis was given when at least one parent reported ever having had asthma or rhinitis.

Information on potential confounders was extracted from data from SOLAR I except for the information regarding the participants' parents (parental SES, and parental history of asthma and rhinitis), for which ISAAC II data were used.

\section{Statistical analysis}

The distribution of variables in the study population by sex was described in absolute numbers and percentages. Chi-squared tests were performed to check the independence of the results.

In multiple logistic regression analyses, the three outcomes, as well as the two exposures, were analysed separately. The number of participants included in the regression model varied due to the exclusion of participants who reported wheezing, asthma or rhinoconjunctivitis at baseline with respect to the outcome variables. Therefore, 1768 participants were included in the regression model for incident wheezing as the outcome variable. For the analysis of incident asthma, 1925 participants were included and 1578 for incident rhinoconjunctivitis (figure 1). Because of the differences in exposure and the different risk of developing asthma, we stratified for sex. The regression models were adjusted for the potential confounders. The variance inflation factors were assessed and implied that no multicollinearity was given. 


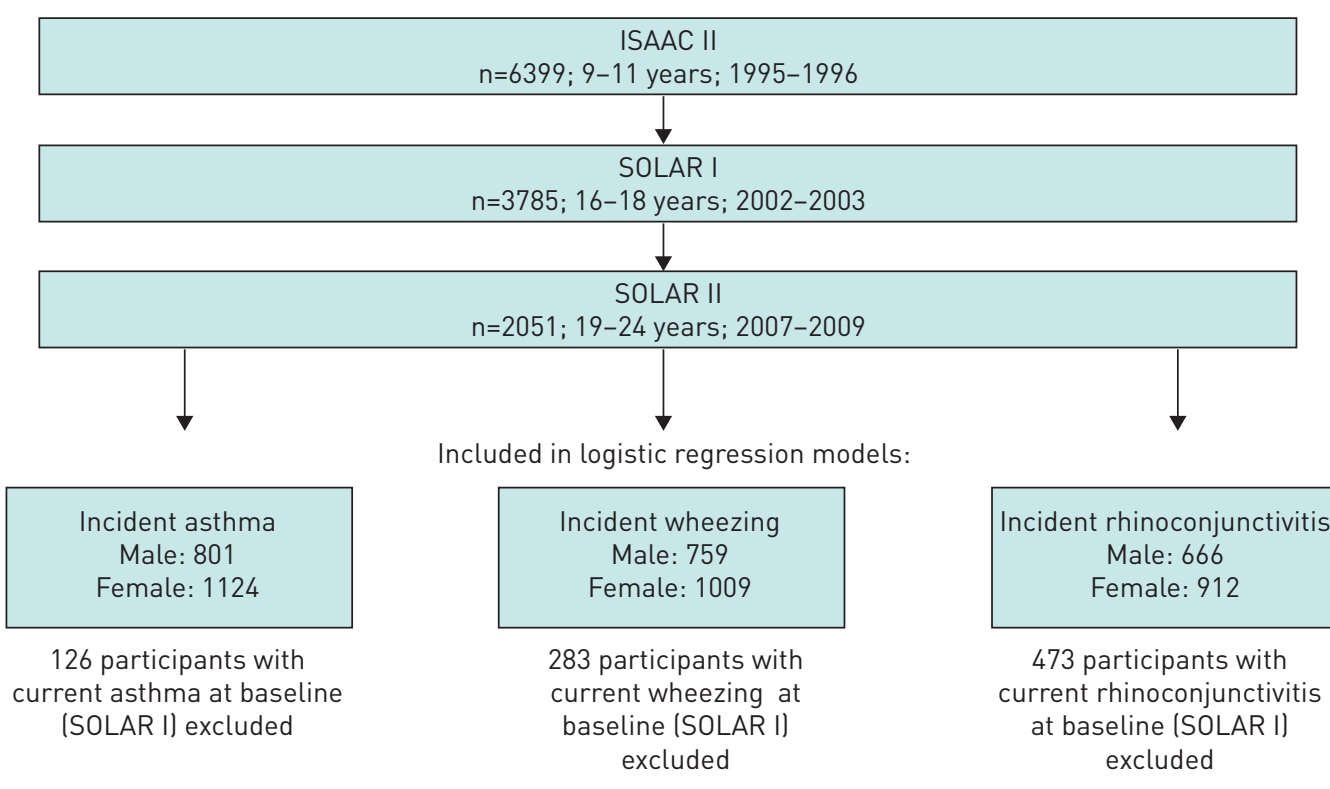

FIGURE 1 Study population included in ISAAC II (the second phase of the International Study of Asthma and Allergies in Childhood) with its two follow-ups SOLAR (Study on Occupational Allergy Risks) I and II, and participants included in the present analyses.

$\mathrm{R}$ version 3.5.0 ( $\mathrm{R}$ Foundation for Statistical Computing, Vienna, Austria) was used to perform the statistical analysis. Missing data were considered to be missing at random. The R package "mice" was used to impute the data applying $m=5$ imputations [31]. In addition, all models were repeated using nonimputed data without major changes in the effect estimates. The regression models analysing the nonimputed data, and the odds ratios and $95 \%$ confidence intervals of the potential confounders of the adjusted models are provided in the tables S1-S5.

\section{Sensitivity analysis}

For the sensitivity analysis, the dichotomised self-reported nickel allergy exposure variable (never or ever) was changed into four categories (never, persistent, remittent or incident). Participants that neither at the first nor at second survey reported being allergic to nickel were categorised as never having had nickel allergy. For the opposite scenario, participants reporting nickel allergy at both time points were grouped in the persistent nickel allergy category. The remittent nickel allergy group comprised those with nickel allergy at baseline and no nickel allergy at follow-up. Participants with no nickel allergy at baseline but nickel allergy at follow-up were categorised as having incident nickel allergy. Since there was no male participant with incident wheezing and incident nickel allergy, the incident nickel allergy category was excluded from the analysis for incident wheezing in males.

\section{Results}

\section{Descriptive data}

The study population comprised more females (58.1\%) than males (41.9\%). Females reported nickel allergy and pierced ears more often, and they were more likely to have ever smoked than male participants (table 1). Overall, the incidence of the three outcomes between SOLAR I and II was 126 for wheezing, 37 for asthma and 227 for rhinoconjunctivitis. Incidence did not differ by sex (figure 2).

\section{Associations between nickel allergy and incident wheezing}

An association between self-reported nickel allergy and incident wheezing was shown for males and females (table 2). After adjusting for potential confounders, this association was no longer statistically significant in females (adjusted OR 1.57, 95\% CI 0.96-2.57). Having pierced ears was only statistically significantly associated with increased incidence of wheezing in males (adjusted OR 2.26, 95\% CI 1.10-4.62) and not in females (adjusted OR 1.27, 95\% CI 0.49-3.27) without indication of effect modification by sex. These results were basically confirmed when categorising the exposure (table S6). 


\begin{tabular}{|c|c|c|c|c|}
\hline & Missing & Males & Females & Chi-squared test $p$-value \\
\hline Nickel allergy & \multirow[t]{3}{*}{$52(2.5 \%)$} & & & \multirow[t]{3}{*}{$<0.001$} \\
\hline Never & & $772(89.8 \%)$ & $788(66.2 \%)$ & \\
\hline Ever & & $67(7.8 \%)$ & $372(31.2 \%)$ & \\
\hline Pierced ears & \multirow[t]{2}{*}{$6(0.3 \%)$} & & & \multirow[t]{2}{*}{$<0.001$} \\
\hline Yes & & $162(18.8 \%)$ & $1082(90.8 \%)$ & \\
\hline Smoking status & \multirow[t]{2}{*}{$14(0.7 \%)$} & & & \multirow[t]{2}{*}{$<0.001$} \\
\hline Ever & & $260(30.2 \%)$ & $458(38.5 \%)$ & \\
\hline Parental SES & \multirow[t]{2}{*}{$29(1.4 \%)$} & & & \multirow{2}{*}{0.37} \\
\hline High $^{\#}$ & & $513(59.7 \%)$ & $677(56.8 \%)$ & \\
\hline Participants' SES & \multirow[t]{2}{*}{$10(0.5 \%)$} & & & \multirow[t]{2}{*}{0.09} \\
\hline High $^{\#}$ & & $487(56.6 \%)$ & $718(60.3 \%)$ & \\
\hline Study centre & \multirow[t]{2}{*}{$0(0.0 \%)$} & & & \multirow[t]{2}{*}{0.43} \\
\hline Dresden & & $428(49.8 \%)$ & $615(51.6 \%)$ & \\
\hline Parental history of asthma & \multirow{2}{*}{$55(2.7 \%)$} & & & \multirow{2}{*}{0.30} \\
\hline Yes ${ }^{\pi}$ & & $88(10.2 \%)$ & $103(8.6 \%)$ & \\
\hline Parental history of rhinitis & \multirow[t]{2}{*}{$43(2.1 \%)$} & & & \multirow[t]{2}{*}{0.17} \\
\hline Yes & & $312(36.3 \%)$ & $398(33.2 \%)$ & \\
\hline
\end{tabular}

SES: socioeconomic status. ${ }^{\#}: \geqslant 12$ years of school attendance for participant or at least one parent; ${ }^{\text {ๆ: }}$ at least one parent ever had asthma or rhinitis.

\section{Associations between nickel allergy and incident asthma}

In males, the logistic regression model yielded a statistically significant association between self-reported nickel allergy and incident asthma (adjusted OR 4.34, 95\% CI 1.22-15.41). For pierced ears, this association was no longer statistically significant after adjustment (adjusted OR 3.19, 95\% CI 0.91-11.15). For females, no indication of an association between nickel allergy or pierced ears and incident asthma was observed (table 3). Categorisation of the exposure yielded similar results (table S6).

\section{Associations between nickel allergy and incident rhinoconjunctivitis}

No significant association with any of the two exposure variables and incident rhinoconjunctivitis was observed for males or females (table 4). Categorising the exposure revealed an association between incident nickel allergy and incident rhinoconjunctivitis in males (adjusted OR 4.45, 95\% CI 1.19-16.67) (table S6).

Nonstratified analysis yielded similar results, with a significant association for nickel allergy and incident wheezing, and no association for incident asthma/rhinoconjunctivitis (table S7). The results of the regression models with interaction terms confirmed our results (table S8).

FIGURE 2 Total and relative frequency of participants with incident asthma, incident wheezing and incident rhinoconjunctivitis between SOLAR (Study on Occupational Allergy Risks) I and II by sex.

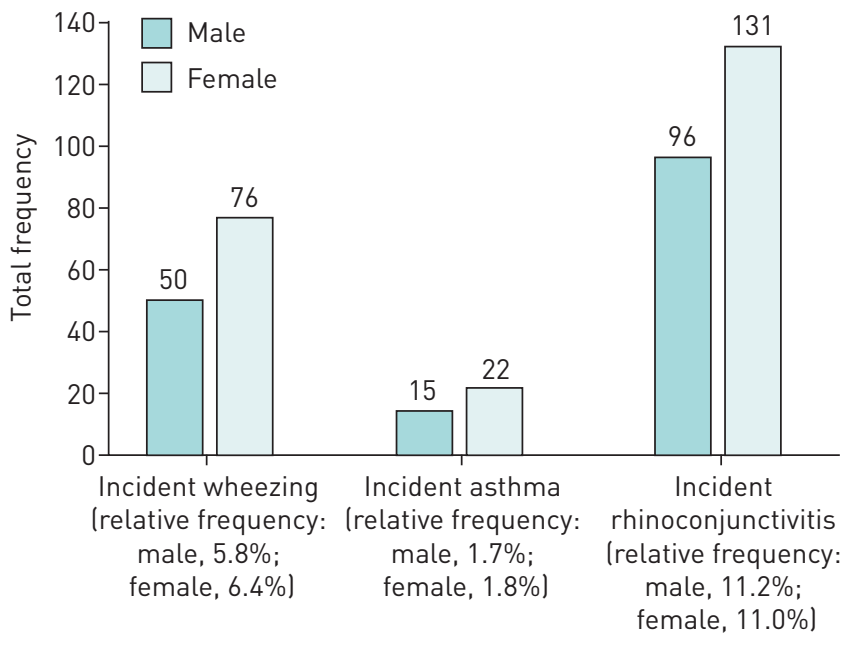


TABLE 2 Adjusted and unadjusted multiple logistic regression model for the association of self-reported nickel allergy and pierced ears with incident wheezing for males and females; imputed data, excluding those with wheezing at baseline

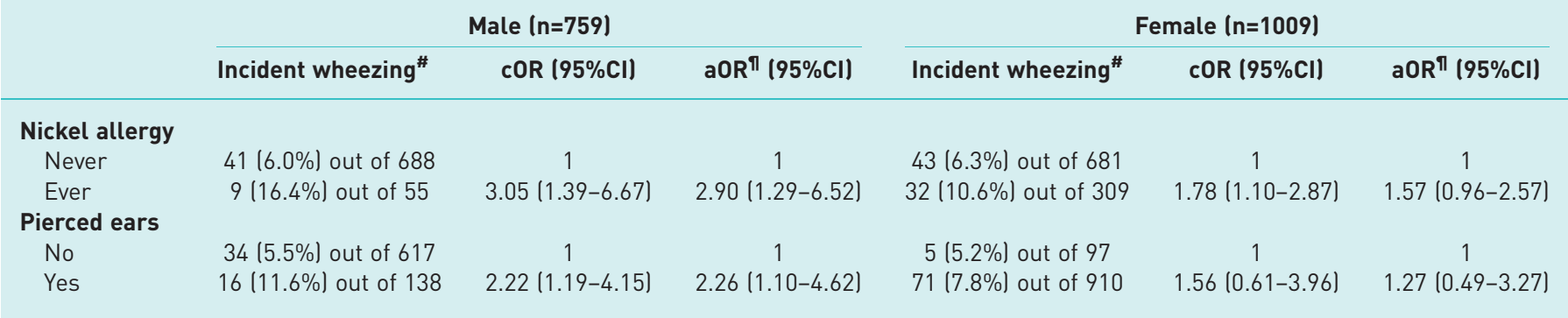

cOR: crude odds ratio; aOR: adjusted odds ratio. ": obtained from nonimputed data; ๆ: adjusted for potential confounders (smoking status, parental socioeconomic status (SES), participant's SES, study centre and parental history of asthma).

\section{Discussion}

In the present study, we aimed to investigate whether self-reported nickel allergy is associated with incident wheezing, asthma and rhinoconjunctivitis in young German adults. We separately analysed the data from male and female participants, and our analysis indicated an association between nickel allergy and incident wheezing and asthma. The observed associations differed between males and females, but confidence intervals were still overlapping thus not indicating effect modification by sex.

We observed strong effect estimates for nickel allergy and incident wheezing in males and females. The analyses of incident wheezing as the outcome had more statistical power than the analyses of incident asthma. Wheezing is a more sensitive means to assess asthma but the results may be less specific [32]. In our analysis, the statistical power of the analyses of incident asthma was limited. Due to the small number of participants, stratification for atopy was not possible. Regarding incident rhinoconjunctivitis, we observed no significant association with self-reported nickel allergy or pierced ears in either males or females. When stratifying for smoking status (never-smoker/ever-smoker) as a risk factor for contact allergy as well as wheezing, associations were stronger for never-smokers (table S9).

So far, three studies have investigated the association between contact allergy and atopy in a general population, with two of them analysing adolescents $[4,22]$ and the other analysing a broader age range (15-69 years) [21]. Nickel allergy as most prevalent contact allergy was investigated separately in these studies. Patch tests were used to determine nickel allergy [4, 21, 22]. In accordance with the results of our analysis of incident rhinoconjunctivitis, none of these studies found an association between nickel allergy and atopy. None of these studies used asthma symptoms or wheezing as a standalone outcome. Asthma and rhinoconjunctivitis share IgE-mediated inflammatory mechanisms but there are still differences that may explain our results showing no association for incident rhinoconjunctivitis but for incident wheezing/ asthma. For severe asthma other mechanisms, not mediated by IgE are known. Additionally, asthma is more likely to occur due to low molecular weight agents than rhinitis, and the intensity of inflammation in asthma and rhinitis may differ [33-35]. Two other studies focussing on the coexistence of contact allergies in general in patients with allergic rhinitis and asthma found an inverse association between contact

TABLE 3 Adjusted and unadjusted multiple logistic regression model for the association of self-reported nickel allergy and pierced ears with incident asthma for males and females; imputed data, excluding those with asthma at baseline

\begin{tabular}{|c|c|c|c|c|c|c|}
\hline & \multicolumn{3}{|c|}{ Male ( $n=801)$} & \multicolumn{3}{|c|}{ Female ( $n=1124$ ) } \\
\hline Never & $11(1.5 \%)$ out of 727 & 1 & 1 & $15(2.0 \%)$ out of 747 & 1 & 1 \\
\hline Ever & $4(7.1 \%)$ out of 56 & $4.67(1.44-15.18)$ & $4.34(1.22-15.41)$ & $7(2.0 \%)$ out of 346 & $1.04(0.41-2.6)$ & $0.93(0.37-2.38)$ \\
\hline \multicolumn{7}{|c|}{ Pierced ears } \\
\hline No & $9(1.4 \%)$ out of 648 & 1 & 1 & $2(1.9 \%)$ out of 103 & 1 & 1 \\
\hline
\end{tabular}


TABLE 4 Adjusted and unadjusted multiple logistic regression model for the association of self-reported nickel allergy and pierced ears with incident rhinoconjunctivitis for males and females; imputed data, excluding those with rhinoconjunctivitis at baseline

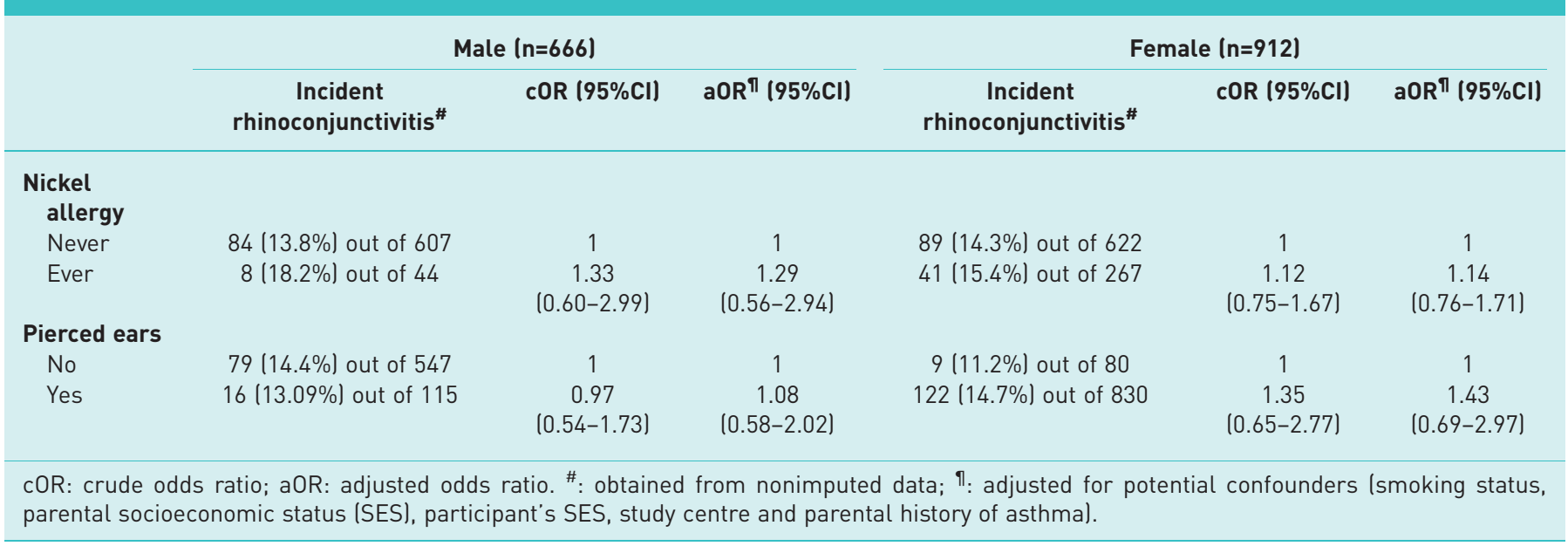

Male $(n=666)$

allergies and atopic dermatitis, allergic rhinitis, allergic conjunctivitis and asthma [23, 36]. Nonetheless, a case-control study among 40 asthmatics and nonasthmatics indicated higher odds of sensitisation to nickel among cases compared to controls [24]. An increased frequency of contact allergy in atopics may be due to an altered cell-mediated immunity and a lower threshold for developing contact allergy in atopics [3, 36]. Case reports about asthma and rhinitis in association with occupational nickel exposure or work-related nickel allergy showed that the inhalation of nickel can cause respiratory symptoms [13-18].

The major strength of our study is the longitudinal design, which provides the opportunity to follow the participants over a long time. Due to our definition of the exposures and our outcome definitions we can ensure that the exposure preceded the outcomes. A negative aspect of the long follow-up time of our study is the loss of participants, which may cause selection bias. Previous analysis showed that participants with atopic diseases in ISAAC II and those whose parents had allergic diseases were more likely to participate in the follow-up studies [26]. In our study sample, selection bias should be limited though, since in a nonresponder analysis considering the outcomes and the exposures, we did not observe statistically significant differences between participants and nonparticipants (data not shown).

We analysed the association between self-reported nickel allergy and incident wheezing, asthma and rhinoconjunctivitis based on questionnaire answers and not based on objective measurements. Our variables are thereby susceptible to differential misclassification. The definitions of the outcome variables were based on standardised and validated questions from ISAAC, which were used throughout the different study phases [28]. The question on whether the participants have nickel allergy was integrated later in the SOLAR questionnaire. Studies analysing the validity of self-reported nickel allergy found a positive predictive value (PPV) ranging from $32 \%$ to $71 \%$; thus, the validity of self-reported nickel allergy is rather low but still reasonable [5,37, 38]. As part of the clinical examination in SOLAR II, 288 participants were patch tested for nickel sulfate. With a PPV of $44 \%$, the validity of self-reported nickel allergy is thus in accordance to the findings of other studies. In general, comparing patch tests to self-reports revealed that self-reports overestimate the prevalence of nickel allergy [5, 37, 38]. In population-based studies, the response decreases when clinical examinations are involved. For patch tests, participants must visit the clinic twice (first to apply the patch and then to read the patch test). As a result, only $14 \%$ of the participants answering the SOLAR II questionnaire agreed to the test.

Because of the adoption of the nickel directive in 1994, the nickel release of consumer objects should be limited and pierced ears should not be associated with nickel allergy anymore. After the nickel legislation, there was indeed a decrease in the observed prevalence of nickel allergy in females aged 18-35 years and in dermatitis patients [39]. Unfortunately, there was no further decrease. Investigation has shown that ear piercings still exceed the nickel release threshold and therefore, nickel allergy remains highly prevalent [39, 40]. Pierced ears can still be considered an indirect measurement for nickel allergy. In our analysis, the statistical power of pierced ears in females was very low as piercing ears was common among them. This may explain why we observed an association of pierced ears with incident wheezing only in male participants. Contrary to our expectations, no effect modification could be proven due to overlapping 
confidence intervals. Furthermore, the participants were asked whether they have pierced ears and not if they wear earrings. This may lead to systematic bias in our analysis.

Unmeasured confounding should be limited but cannot be excluded in our study. We adjusted for the most important confounders known from literature. Occupation could be considered an additional confounder. The literature concerning occupational risk factors for nickel allergy is based on just a number of jobs with very specific nickel exposures. Therefore, and since our study population consisted of a young age group that was just at the beginning of work life, we did not consider occupation as a potential confounder [19,41]. Because we analysed data from young German adults, our results are not fully generalisable to other age groups and countries.

Overall, our results indicate that self-reported nickel allergy is associated with incident wheezing in young German males and females. Even though nickel allergy and asthma belong to two different hypersensitivity types with different mechanisms, our results indicate an association. It is important to further investigate whether this association is due to environmental or genetic predisposition, or due to an overlap of the mechanisms.

Author contributions: L. Kolberg, F. Forster, J. Gerlich, G. Weinmayr, J. Genuneit, D. Windstetter, C. Vogelberg, E. von Mutius, D. Nowak, H. Drexler, T. Schäfer and K. Radon contributed to the conception and design of the study, and the data acquisition, analysis, and/or interpretation, and the revision of the manuscript. L. Kolberg, F. Forster and K. Radon drafted the manuscript. All authors approved the final version of the manuscript and agreed to the submission to the journal.

Support statement: The ISAAC Phase Two study in Dresden and Munich was funded by the German Ministry of Education and Research (01 EE 9411-3). The SOLAR I study was supported by the German Ministry for Economy and Labour. The SOLAR II study was funded by the German Federal Institute for Occupational Safety and Health and the German Ministry of Labour and Social Affairs.

Conflict of interest: L. Kolberg has nothing to disclose. F. Forster has nothing to disclose. J. Gerlich reports grants from German Federal Ministry of Labour, grants from German Research Foundation, during the conduct of the study. G. Weinmayr has nothing to disclose. J. Genuneit has nothing to disclose. D. Windstetter has nothing to disclose. C. Vogelberg reports grants from Federal Ministry of Labor and Social Affairs, grants from Federal Office for Occupational Safety and Occupational Medicine and Federal Ministry of Labor and Social Affairs, during the conduct of the study. E. von Mutius reports grants from German Research Foundation (DFG - Deutsche Forschungsgemeinschaft), during the conduct of the study; personal fees from OM Pharma, personal fees from Peptinnovate, personal fees from Boehringer Ingelheim International $\mathrm{GmbH}$, personal fees from HAL Allergie $\mathrm{GmbH}$ and personal fees from Nestle Deutschland AG, outside the submitted work. D. Nowak has nothing to disclose. H. Drexler has nothing to disclose. T. Schäfer has nothing to disclose. K. Radon has nothing to disclose.

\section{References}

1 Ahlström MG, Thyssen JP, Wennervaldt M, et al. Nickel allergy and allergic contact dermatitis: a clinical review of immunology, epidemiology, exposure, and treatment. Contact Derm 2019; 81: 227-241.

2 Lagrelius M, Wahlgren C-F, Matura M, et al. High prevalence of contact allergy in adolescence: results from the population-based BAMSE birth cohort. Contact Derm 2016; 74: 44-51.

3 Dotterud LK, Smith-Sivertsen T. Allergic contact sensitization in the general adult population: a population-based study from Northern Norway. Contact Derm 2007; 56: 10-15.

4 Mortz CG, Lauritsen JM, Bindslev-Jensen C, et al. Contact allergy and allergic contact dermatitis in adolescents: prevalence measures and associations. The Odense Adolescence Cohort Study on Atopic Diseases and Dermatitis (TOACS). Acta Derm Venereol 2002; 82: 352-358.

5 Fors R, Persson M, Bergström E, et al. Nickel allergy - prevalence in a population of Swedish youths from patch test and questionnaire data. Contact Derm 2008; 58: 80-87.

6 Mortz CG, Lauritsen JM, Bindslev-Jensen C, et al. Nickel sensitization in adolescents and association with ear piercing, use of dental braces and hand eczema. The Odense Adolescence Cohort Study on Atopic Diseases and Dermatitis (TOACS). Acta Derm Venereol 2002; 82: 359-364.

7 European Parliament, European Council. European Parliament and Council directive 94/27/EC. Off J Eur Commun 1994; L188: 1-2.

8 Lidén C. Legislative and preventive measures related to contact dermatitis. Contact Derm 2001; 44: 65-69.

9 Ahlström MG, Menné T, Thyssen JP, et al. The European nickel regulation and changes since its introduction Contact Derm 2017; 76: 382-384.

10 Hansen TE, Evjenth B, Holt J. Increasing prevalence of asthma, allergic rhinoconjunctivitis and eczema among schoolchildren: three surveys during the period 1985-2008. Acta Paediatr 2013; 102: 47-52.

11 Mortz CG, Lauritsen JM, Bindslev-Jensen C, et al. Prevalence of atopic dermatitis, asthma, allergic rhinitis, and hand and contact dermatitis in adolescents. The Odense Adolescence Cohort Study on Atopic Diseases and Dermatitis. Br J Dermatol 2001; 144: 523-532.

12 Humbert M, Bousquet J, Bachert C, et al. IgE-mediated multimorbidities in allergic asthma and the potential for omalizumab therapy. J Allergy Clin Immunol Pract 2019; 7: 1418-1429.

13 Malo JL, Cartier A, Gagnon G, et al. Isolated late asthmatic reaction due to nickel sulphate without antibodies to nickel. Clin Allergy 1985; 15: 95-99.

14 Estlander T, Kanerva L, Tupasela O, et al. Immediate and delayed allergy to nickel with contact urticaria, rhinitis, asthma and contact dermatitis. Clin Exp Allergy 1993; 23: 306-310. 
15 Fernández-Nieto M, Quirce S, Carnés J, et al. Occupational asthma due to chromium and nickel salts. Int Arch Occup Environ Health 2006; 79: 483-486.

16 McConnell LH, Fink JN, Schlueter DP, et al. Asthma caused by nickel sensitivity. Ann Intern Med 1973; 78: 888-890.

17 Castano R, Suarthana E. Occupational rhinitis due to steel welding fumes. Am J Ind Med 2014; 57: 1299-1302.

18 Niordson AM. Nickel sensitivity as a cause of rhinitis. Contact Derm 1981; 7: 273-274.

19 Uter W, Pfahlberg A, Gefeller O, et al. Risk factors for contact allergy to nickel - results of a multifactorial analysis. Contact Derm 2003; 48: 33-38.

20 Nielsen $\mathrm{NH}$, Linneberg A, MennE T, et al. Incidence of allergic contact sensitization in Danish adults between 1990 and 1998; the Copenhagen Allergy Study, Denmark. Br J Dermatol 2002; 147: 487-492.

21 Nielsen NH, Menné T. The relationship between IgE-mediated and cell-mediated hypersensitivities in an unselected Danish population: The Glostrup Allergy Study, Denmark. Br J Dermatol 1996; 134: 669-672.

22 Spiewak R. Atopy and contact hypersensitivity: a reassessment of the relationship using objective measures. Ann Allergy Asthma Immunol 2005; 95: 61-65.

23 Thyssen JP, Johansen JD, Linneberg A, et al. The association between contact sensitization and atopic disease by linkage of a clinical database and a nationwide patient registry. Allergy 2012; 67: 1157-1164.

24 Gül U, Cakmak SK, Olcay I, et al. Nickel sensitivity in asthma patients. J Asthma 2007; 44: 383-384.

25 de Marco R, Locatelli F, Sunyer J, et al. Differences in incidence of reported asthma related to age in men and women. A retrospective analysis of the data of the European Respiratory Health Survey. Am J Respir Crit Care Med 2000; 162: 68-74.

26 Heinrich S, Peters A, Kellberger J, et al. Study on occupational allergy risks (SOLAR II) in Germany: design and methods. BMC public health 2011; 11: 298.

27 Weiland SK, Björkstén B, Brunekreef B, et al. Phase II of the International Study of Asthma and Allergies in Childhood (ISAAC II): rationale and methods. Eur Respir I 2004; 24: 406-412.

28 Asher MI, Keil U, Anderson HR, et al. International Study of Asthma and Allergies in Childhood (ISAAC) rationale and methods. Eur Respir J 1995; 8: 483-491.

29 Burney PGJ, Luczynska C, Chinn S, et al. The European Community Respiratory Health Survey. Eur Respir J 1994; 7: 954-960.

30 Kellberger J, Peters-Weist AS, Heinrich S, et al. Predictors of work-related sensitisation, allergic rhinitis and asthma in early work life. Eur Respir J 2014; 44: 657-665.

31 van Buuren S, Groothuis-Oudshoorn K. mice : Multivariate Imputation by Chained Equations in R. J Stat Softw 2011; 45: 1-67.

32 Sistek D, Wickens $\mathrm{K}$, Amstrong $\mathrm{R}$, et al. Predictive value of respiratory symptoms and bronchial hyperresponsiveness to diagnose asthma in New Zealand. Respir Med 2006; 100: 2107-2111

33 Malo JL, Lemiere C, Desjardins A, et al. Prevalence and intensity of rhinoconjunctivitis in subjects with occupational asthma. Eur Respir J 1997; 10: 1513-1515.

34 Bousquet J, Khaltaev N, Cruz AA, et al. Allergic Rhinitis and its Impact on Asthma (ARIA) 2008 update (in collaboration with the World Health Organization, GA²LEN and AllerGen). Allergy 2008; 63: Suppl. 86, 8-160.

35 Bousquet J, Vignola AM, Demoly P. Links between rhinitis and asthma. Allergy 2003; 58: 691-706.

36 Lammintausta K, Kalimo K, Fagerlund VL. Patch test reactions in atopic patients. Contact Derm 1992; 26 : 234-240.

37 Ko LN, Kroshinsky D, Schalock PC. Assessing the validity of self-reported history of rash caused by metal or jewellery. Contact Derm 2018; 78: 208-210.

38 Josefson A, Färm G, Meding B. Validity of self-reported nickel allergy. Contact Derm 2010; 62: 289-293.

39 Ahlström MG, Thyssen JP, Menné T, et al. Prevalence of nickel allergy in Europe following the EU Nickel Directive - a review. Contact Derm 2017; 77: 193-200.

40 Uter W, Wolter J. Nickel and cobalt release from earrings and piercing jewellery - analytical results of a German survey in 2014. Contact Derm 2018; 78: 321-328.

41 Boonchai W, Chaiwanon O, Kasemsarn P. Risk assessment for nickel contact allergy. J Dermatol 2014; 41: 1065-1068. 